\title{
Inertia response from full-power converter-based permanent magnet wind generators
}

\author{
John LICARI, Janaka EKANAYAKE (ه), \\ Ian MOORE
}

\begin{abstract}
With a high penetration of wind turbines, the proportion of synchronous generation in the power system will be reduced at times, thus creating operating difficulties especially during frequency events. Therefore, it is anticipated that many grid operators will demand inertia response from wind turbines. In this article, different ways for emulating inertia response in full-rated power converter-based wind turbines equipped with permanent magnet synchronous generators are considered. Supplementary control signals are added to the controller of the wind turbine to extract stored energy from the rotating mass and DC-link capacitors. Simulations in MATLAB/Simulink show that the inertia response is improved by adding a term proportional to the rate of change of frequency and by extracting the stored energy in the DC-link capacitors.
\end{abstract}

Keywords Inertia response, Frequency response, Full-rated power converter, Wind turbines

\section{Introduction}

Utility scale electrical power systems consist of a number of large generators and a multitude of loads. During a day, the output of generators and the consumption of loads

Received: 1 July 2012 / Accepted: 9 August 2012 / Published online: 5 July 2013

(C) The Author(s) 2013. This article is published with open access at Springerlink.com

J. LICARI, J. EKANAYAKE, I. MOORE, Institute of Energy,

Cardiff University, Cardiff CF243AA, UK

$(\bowtie)$ e-mail: EkanayakeJ@cardiff.ac.uk

J. LICARI

e-mail: LicariJ@cardiff.ac.uk

I. MOORE

e-mail: MooreIF@cardiff.ac.uk

J. EKANAYAKE, University of Peradeniya, Peradeniya,

Sri Lanka vary continuously. In order to maintain the system frequency within statutory limits and to ensure secure operation of the power system, the demand and the generation should be balanced in real time. This balance is principally managed through a combination of automatic and scheduled (nonautomatic) changes in generator output. In the UK, these are termed as response and reserve, respectively. When the system experiences a sudden large generation loss or the connection of a large load, the system frequency reduces rapidly. In such an event, the natural response of generators and some of the loads (commonly known as inertia response) and the response services provided by some generators contain the change in frequency.

Rotating electrical machinery, such as synchronous turbogenerators, synchronous machine (SM), and induction machine (IM) loads will all contribute to system inertia. For the SM, this is due to the rotor shaft being synchronously coupled to the stator field. In the IM case, the rotor shaft is coupled to the stator field asynchronously depending on the slip. Conversely, variable-speed wind turbines do not contribute toward system inertia. This is because such turbines employ a power electronic converter to control the electromagnetic torque for variable-speed operation. This decouples the rotor speed from changes in the system frequency.

With high penetration of wind energy, variable-speed wind turbines will eventually replace some of the synchronous generators which imply that the overall system inertia will be reduced. This creates difficulties for the power system to contain the system frequency after a frequency event.

Even though variable-speed wind turbines do not contribute to the system inertia, the inertia can be emulated using additional control loops. This can be achieved by operating the wind turbine off its maximum power extraction curve which allows for a fractional extraction of the kinetic energy stored in the rotor of a variable-speed 
wind turbine [1-5]. Another method for providing inertia response can be obtained by increasing the torque or power set points to provide an immediate reduction in the system load generation imbalance [6-8]. The former method has the following advantages: the possibility of emulating the inertia response provided by a synchronous plant; the change in turbine rotor speed being small enough not to affect the steady-state power output of the turbine; and the capability of adjusting the speed recovery rate and the peak power output through some control parameter adjustments.

\section{Current practices and grid code requirements}

The Security and Quality of Supply Standard (SQSS) states that the system frequency of the GB network under normal operating conditions should be maintained at $50 \mathrm{~Hz}$ within operational limits of $\pm 0.5 \mathrm{~Hz}$ [9]. The transmission system operator (TSO), National Grid in this case, imposes its own limits of $\pm 0.2 \mathrm{~Hz}$. This is achieved by operating some generators on a governor droop, normally $4 \%$ or less, and classifying it as a continuous service. When the largest available generation in the system is tripped or an abnormal event equal to that loss is endured, the maximum allowed system frequency deviation is $0.8 \mathrm{~Hz}$. At present, the loss of generation considered is $1,320 \mathrm{MW}$, but it is expected to increase to $1,800 \mathrm{MW}$ with the connection of new large generators.

In the event of a sudden failure in generation or the connection of a large load, the system frequency starts dropping (region $O X$ of Fig. 1) at a rate mainly determined by the summation of the angular momentums of all generators and spinning loads. In order to arrest the frequency change and to bring the system back to its normal operation, the TSO asks for frequency response services. The response is classified as an occasional service and has two parts: primary response and secondary response. Primary frequency response can be defined as the minimum increase in power that can be delivered increasingly with time over a period of $10 \mathrm{~s}$ from a generating unit that is available between 10 and $30 \mathrm{~s}$ after a frequency event.

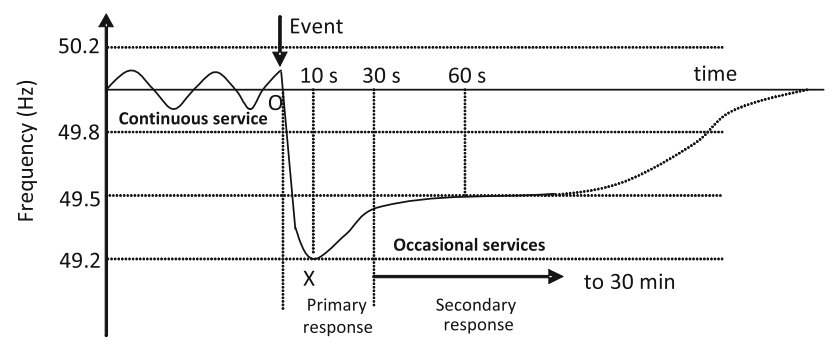

Fig. 1 Frequency control in England and Wales [10]
Secondary response is the minimum increase in active power output which can be sustained between $30 \mathrm{~s}$ and 30 min after a frequency event [10].

Power plants in future power networks can be broadly categorized as synchronous generator-based power plants and electronically controlled and/or connected power plants. It is recognized that most of the wind power plants will fall into the latter category.

Recognizing the operating difficulties arising from a large penetration of wind, many power system operators are making emulated inertia response from wind turbines mandatorily. For example, the European draft code (ENTSO-E) requires an inertia response from power plants above an agreed size. It specifies that [11], "The relevant TSO shall have the right, determined in cooperation with other TSOs in the relevant synchronous area, to require each Power Park Module, which does not inherently have a capability to supply additional active power to the network by its inertia and which is greater than a MW size to be specified by the relevant TSO, to install a feature in the control system which operates the Power Park Module so as to supply additional active power to the network in order to limit the rate of change of frequency following a sudden generation loss."

Full delivery of inertia response must occur within $200 \mathrm{~ms}$, and the initial injected active power supplied to the network shall be in proportion to the rate of change of network frequency. The TSO is required to define the support duration period where the response (now exponentially declining) must remain of a positive magnitude and to define a suitable recovery period.

Further, in Hydro-Quebec grid codes an "inertial response" from wind turbines is required to act during "major frequency deviations" to help in restoring system frequency [12].

The system must reduce large, short-duration frequency deviations at least as much as does the inertia response from a conventional synchronous generator inertia $(\mathrm{H})$ of which equals $3.5 \mathrm{~s}$. This target performance is met, for instance, when the system varies the real power dynamically and rapidly by at least $5 \%$ for about $10 \mathrm{~s}$ when a large, short-duration frequency deviation occurs on the power system.

To achieve this, wind power plants with rated capacity greater than $10 \mathrm{MW}$ should be equipped with a frequency control system that acts during frequency events. For instance, this target performance is met when the system varies the real power dynamically and rapidly by at least $5 \%$ for about $10 \mathrm{~s}$ when a large, short-duration frequency deviation occurs in the power system.

In the UK, the National Grid frequency Response Working Group considered the inertia response capability 


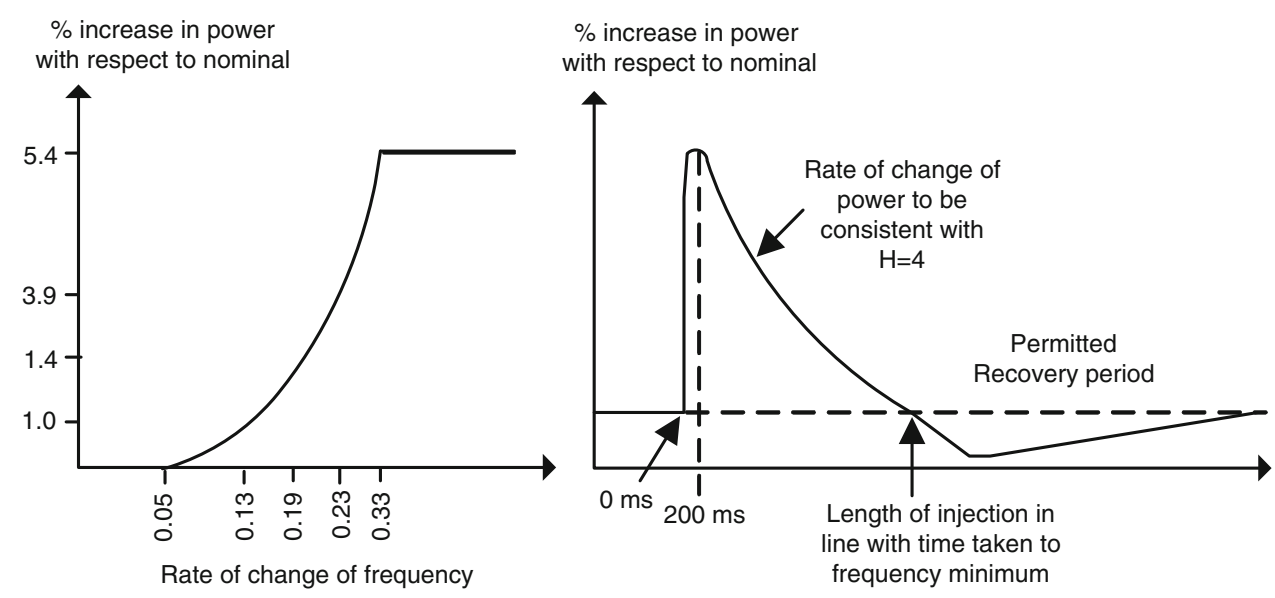

Fig. 2 Proposed synthetic inertia from wind turbines [13]

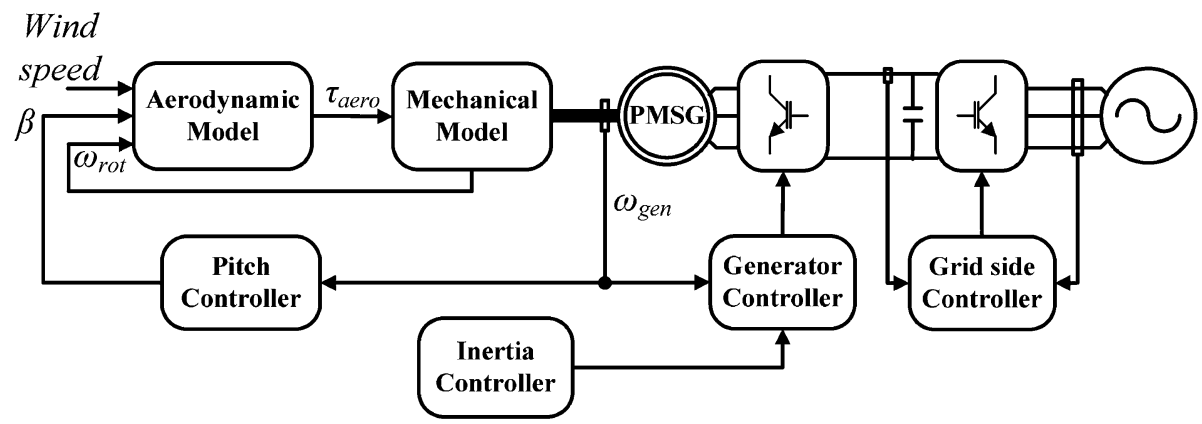

Fig. 3 Schematic diagram of FRPC-PMSG-based wind turbine implemented in Simulink ${ }^{\circledR}$

of wind turbines and proposed the synthetic inertia response shown in Fig. 2 [13]. However, they decided not to include this requirement in the GB Grid Codes.

\section{Modeling of full-rated power converter wind turbine with inertia coupling}

A full-rated power converter (FRPC)-based wind turbine with permanent magnet synchronous generator (PMSG) was considered. A simplified block diagram of the turbine is shown in Fig. 3. The model is composed of the following components: an aerodynamic model, a mechanical representation of a drive-train and the pitch system, and an electrical model consisting of a PMSG, and a back-to-back voltage source converter (VSC). All the parameters of the wind turbine model are given in Appendix 1.

\subsection{Aerodynamic model}

The aerodynamic torque on the shaft of a wind turbine rotor was described by [14] $\tau_{\text {aero }}=\frac{0.5 \rho \pi R^{2} V_{\mathrm{w}}^{3} C_{\mathrm{p}}(\lambda, \beta)}{\omega_{\text {rot }}}$,

where $\rho$ is the air density $\left(\mathrm{kg} / \mathrm{m}^{3}\right) ; A$ is the area swept by the rotor $\left(\mathrm{m}^{2}\right) ; V_{\mathrm{w}}$ is the wind speed $(\mathrm{m} / \mathrm{s}) ; \omega_{\text {rot }}$ is the rotor speed $(\mathrm{rad} / \mathrm{s})$; and $C_{\mathrm{p}}$ is the power coefficient, which is a function of the blade pitch angle $\beta$ (deg) and tip speed ratio $\lambda$.

The rotor speed (derived from the measured generator speed) and the wind speed are used to calculate the tip speed ratio $\lambda$. The resulting $\lambda$ and the pitch angle $\beta$ are used to map the corresponding $C_{\mathrm{p}}$ value, which is then used to calculate the aerodynamic torque $\tau_{\text {aero }}$. The power coefficient was derived from a two-dimensional power coefficient look-up table obtained from a generic 2-MW wind turbine model in Bladed ${ }^{\circledR}$ and is shown in Fig. 4.

\subsection{Mechanical model}

The aerodynamic torque is transferred to the generator shaft via the drive-train. This consists of a LSS that connects the turbine rotor to the gearbox, a gearbox, and a HSS that connects the gearbox to the generator. A two-mass 


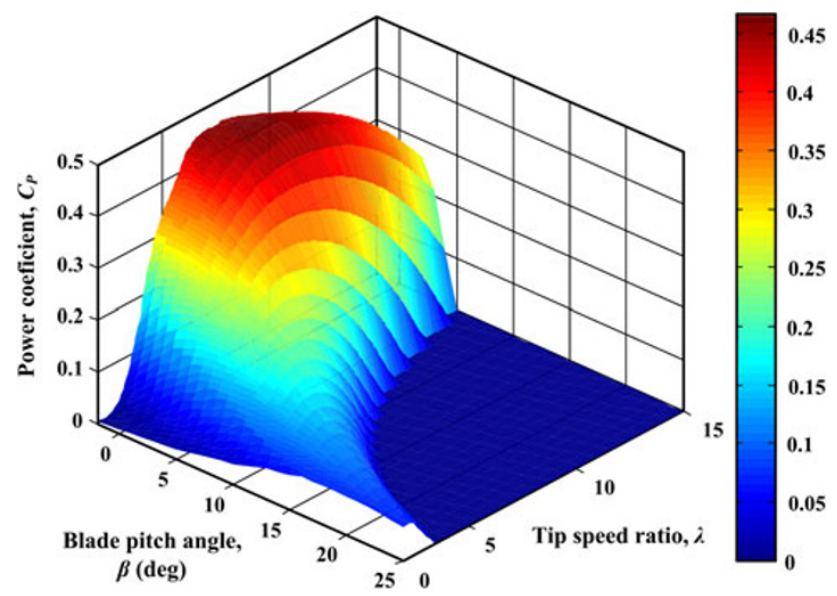

Fig. 4 Variation of the power coefficient $C_{\mathrm{p}}$ as a function of the blade pitch angle $\beta$ and tip speed ratio $\lambda$

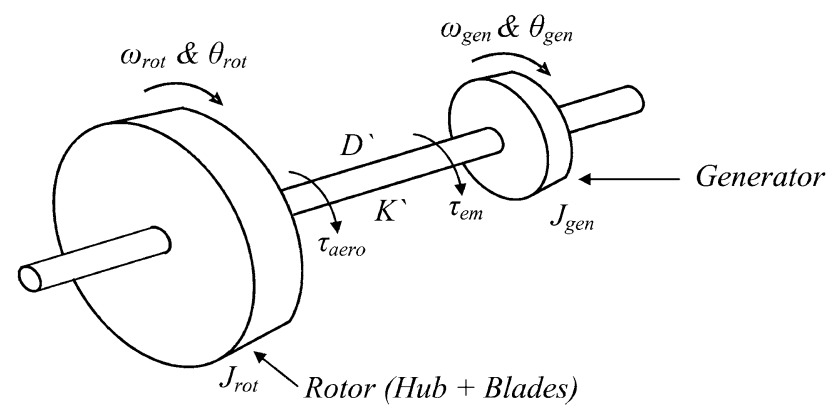

Fig. 5 Two-mass model

model shown in Fig. 5 was used to represent the drive-train dynamics. All wind turbine parameters are included in Appendix 1.

The inputs of the mechanical model are the reaction torque of the generator $\tau_{\text {aero }}^{\prime}$ and the aerodynamic torque $\tau_{\text {aero }}$ The dynamics of the two-mass model referred to the LSS can be described by the following linear differential equations [15-17],

$$
\begin{aligned}
& J_{\text {rot } \frac{\mathrm{d}}{\mathrm{d} t} \omega_{\text {rot }}=} \tau_{\text {aero }}-K^{\prime}\left(\theta_{\text {rot }}-\frac{\theta_{\text {gen }}}{N}\right)-D^{\prime} \\
& \\
& \cdot \frac{\mathrm{d}}{\mathrm{d} t}\left(\theta_{\text {rot }}-\frac{\theta_{\text {gen }}}{N}\right) \\
& J_{\text {gen } \frac{\mathrm{d}}{\mathrm{d} t} \frac{\omega_{\text {gen }}}{N}=}-N \tau_{\text {em }}-K^{\prime}\left(\frac{\theta_{\text {gen }}}{N}-\theta_{\text {rot }}\right)-D^{\prime} \\
& \cdot \frac{\mathrm{d}}{\mathrm{d} t}\left(\frac{\theta_{\text {gen }}}{N}-\theta_{\text {rot }}\right) \\
& \begin{cases}\frac{\mathrm{d}}{\mathrm{d} t} \theta_{\text {rot }}=\omega_{\text {rot }}, \\
\frac{\mathrm{d}}{\mathrm{d} t} \theta_{\text {gen }}=\omega_{\text {gen }},\end{cases}
\end{aligned}
$$

where $\omega_{\text {rot }}$ and $\omega_{\text {gen }}$ are the speeds of the rotor and generator $(\mathrm{rad} / \mathrm{s}) ; \theta_{\text {rot }}$ and $\theta_{\text {gen }}$ are the LSS and HSS angular position (rad); $J_{\text {rot }}$ is the rotor inertia $\left(\mathrm{kgm}^{2}\right) ; J_{\text {gen }}$ is the generator inertia (referred to the LSS) $\left(\mathrm{kgm}^{2}\right)$, and $N$ is the gearbox ratio; $K^{\prime}$ and $D^{\prime}$ are the equivalent LSS and HSS stiffness $(\mathrm{Nm} / \mathrm{rad})$ and damping $(\mathrm{Nms} / \mathrm{rad})$ coefficients referred to the LSS.

\subsection{Electrical model}

On deriving the PMSG model, it was assumed that the stator windings are balanced with sinusoidal distributed magnetomotive force, saturation, and parameters changes are neglected and that no saliency is present. The PMSG is modeled as [18]

$v_{\mathrm{s} d}=i_{\mathrm{s} d} R_{\mathrm{s}}+\frac{\mathrm{d}}{\mathrm{d} t} i_{\mathrm{s} d} L_{d}-\omega_{\mathrm{r}} L_{q} i_{\mathrm{s} q}$,

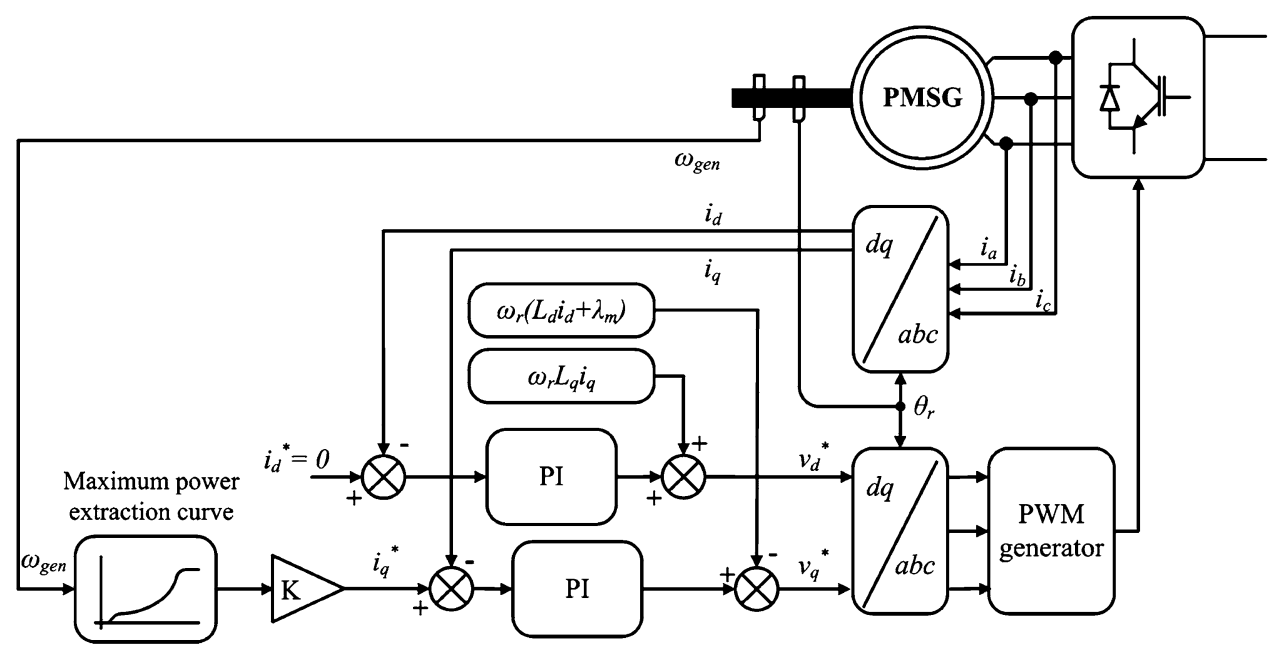

Fig. 6 Field-oriented control scheme for PMSG 


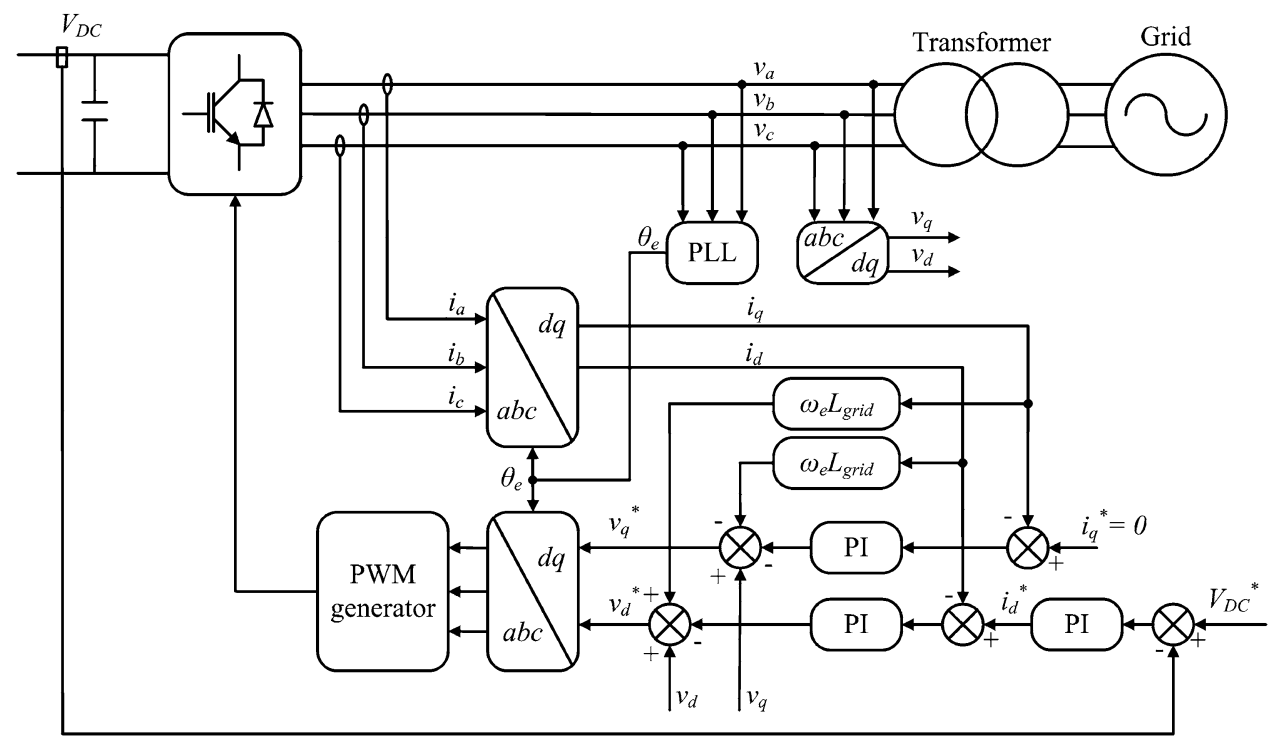

Fig. 7 Vector control scheme for grid-side converter

$v_{\mathrm{s} q}=i_{\mathrm{s} q} R_{\mathrm{s}}+\frac{\mathrm{d}}{\mathrm{d} t} i_{\mathrm{s} q} L_{q}+\omega_{\mathrm{r}} L_{d} i_{\mathrm{s} d}+\omega_{\mathrm{r}} \lambda_{\mathrm{m}}$

$\tau_{\mathrm{em}}=\frac{3}{2} n_{\mathrm{pp}}\left[\lambda_{\mathrm{m}}+\left(L_{d}-L_{q}\right) i_{d}\right] i_{q}$,

where $\omega_{\mathrm{r}}$ is the electrical rotor speed $(\mathrm{rad} / \mathrm{s}) ; L_{d}$ and $L_{q}$ are the equivalent self-inductances of the stator in the $d q$ frame $(\mathrm{H}) ; v_{\mathrm{s} d}$ and $v_{\mathrm{s} q}$ are the equivalent stator voltages in the $d q$ frame $(\mathrm{V}) ; \lambda_{\mathrm{m}}$ is the flux linkage of the permanent magnet (Vs); $i_{\mathrm{s} d}$ and $i_{\mathrm{s} q}$ are the equivalent stator currents in the $d q$ frame $(\mathrm{A}) ; R_{\mathrm{s}}$ is the stator resistance $(\Omega) ; n_{\mathrm{pp}}$ is the number of pole pairs; and $\tau_{\mathrm{em}}$ is the electromagnetic torque.

\subsection{Generator-side converter control}

The block diagram of the vector control scheme used in this study is shown in Fig. 6. The generator controller was derived assuming that the $d$-axis is aligned with the flux produced by the permanent magnet, $\lambda_{\mathrm{m}}$. The $q$-axis current is then used to control the electromagnet torque of the generator.

The reference $d$-axis current $i_{d}^{*}$ was set to zero, whereas the reference $q$-axis current $i_{q}^{*}$ was computed using

$i_{q}^{*}=\tau_{\mathrm{em}}^{*} \frac{2}{3 n_{\mathrm{pp}} \cdot \lambda_{\mathrm{m}}}$, where $\tau_{\mathrm{em}}^{*}$ is the optimal torque reference for maximum power extraction. This was obtained using a look-up table.

\subsection{Grid-side converter control}

The control scheme used for the grid-side converter was vector control, where the $d$-axis current was used to control the DC-link voltage and thus the active power flow into the grid, whereas the $q$-axis current was used to control the reactive power flow. The control scheme is shown in Fig. 7.

\subsection{Pitch controller}

Above rated wind speed, the aerodynamic torque is deliberately limited by the pitch controller not to exceed the maximum turbine ratings. The pitch angle controller consists of a PI controller equipped with an anti-windup circuit that generates a pitch angle reference from the generator speed error. A gain scheduling was used to compensate for the aerodynamic nonlinearities. The pitch mechanism consists of an actuator model represented by a first-order lag and a limiter for both the pitch angle and its

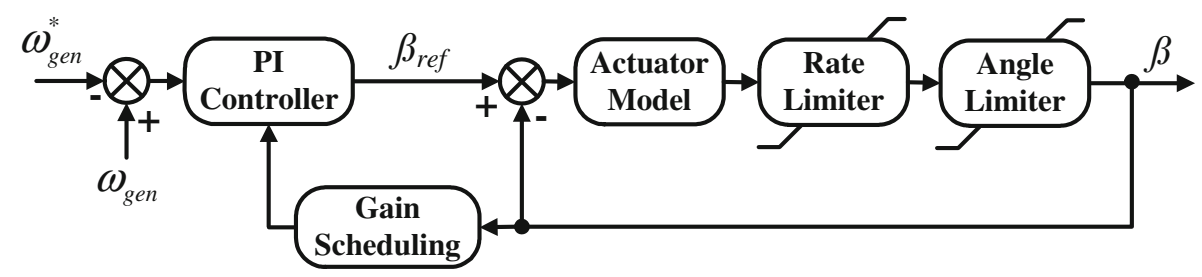

Fig. 8 Pitch controller model 


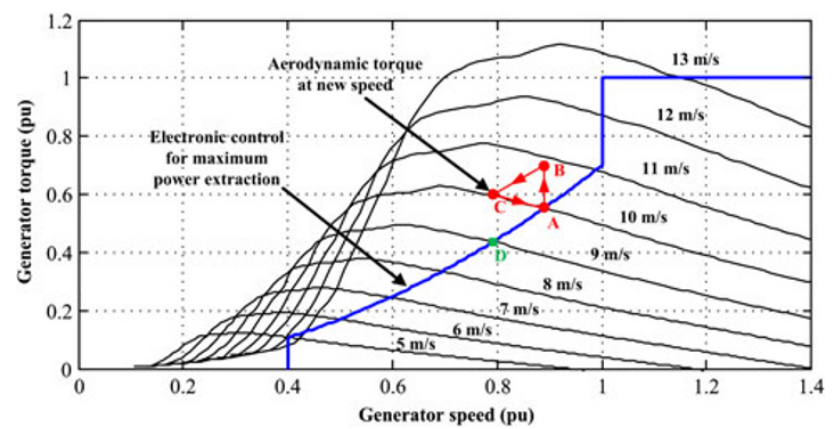

Fig. 9 Torque-speed characteristic of a FRPC-PMSG-based wind turbine

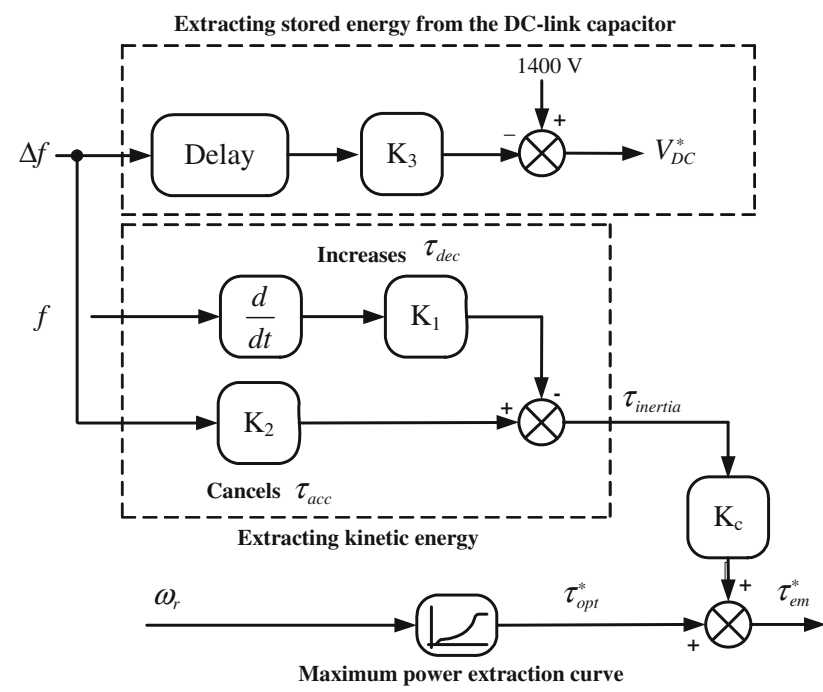

Fig. 10 Supplementary controller to obtain inertia response

rate of change as shown in Fig. 8. The pitch controller parameters are given in Appendix 2.

\section{Inertia controller}

\subsection{Extracting kinetic energy from the rotating mass}

The emulated inertia response of a FRPC-PMSG-based wind turbine can be explained using the torque-speed curves shown in Fig. 9.

In order to obtain the inertia response, a supplementary control signal was added to the generator-side torque controller as shown in Fig. 10.

When there is a frequency event, the deceleration torque $\tau_{\mathrm{dec}}$ becomes nonzero. This results in an increase in the net torque demand $\tau_{\mathrm{em}}^{*}$ to the generator torque controller (point $B$ in Fig. 9). At this point, the power output from the generator increases proportionally to the deceleration torque. Assuming that the wind speed does not change (i.e., the aerodynamic torque available is constant), the extra power is extracted from the kinetic energy in the rotor. This forces the rotor to slow down, and another operating point (point $C$ ) is reached. At this speed, the maximum power extraction curve outputs a new reference torque $\tau_{\mathrm{opt}}^{*}$ for the generator (point $D$ ). The difference between the aerodynamic torque (point $C$ ) and the new generator torque reference (point $D$ ) results in an acceleration torque. This acts as a restoring torque for the speed change, and the rotor accelerates. During this acceleration, the power output from the wind turbine is less than that before the frequency event. This is undesirable during inertia response. In order to mitigate this effect, an additional term $\tau_{\text {acc }}$ proportional to $\Delta f$ in the inertia coupling loop was used. As shown in Fig. 10 (extracting kinetic energy), one loop acts to increase the decelerating torque (proportional to $\mathrm{d} f / \mathrm{d} t$ ) $[2-5,8]$, and the other delays the acceleration of the rotor (proportional to $\Delta f$ ) [8].

\subsection{Extracting stored energy from the DC-link capacitors}

The DC-link capacitors of the FRPC-PMSG-based wind turbines store a considerable amount of energy during normal operation. Some of this energy can be extracted to aid inertia response. Therefore, another control loop (extracting stored energy from the DC-link capacitors shown in Fig. 10) acting on a delayed signal of $\Delta f$ was used. This control action was achieved by reducing the reference voltage of the DC-link (grid-side controller) proportional to the frequency signal $\Delta f$ as shown in the uppermost loop in Fig. 10.

\section{Simulation results}

The FRPC-PMSG-based wind turbine model shown in Fig. 3 was modeled in MATLAB/Simulink. In order to mimic typical frequency change in a power system, the frequency variation shown in Fig. 11 was applied to the inertia controller shown in Fig. 10. The inertia response of the FRPC-PMSG-based wind turbine was obtained by

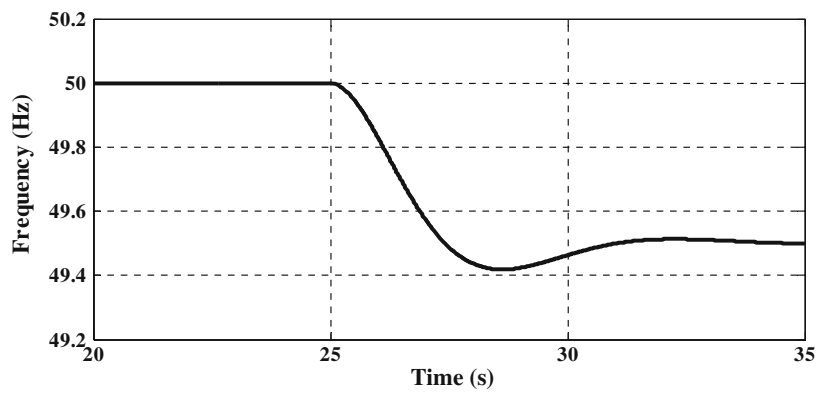

Fig. 11 Frequency deviation 


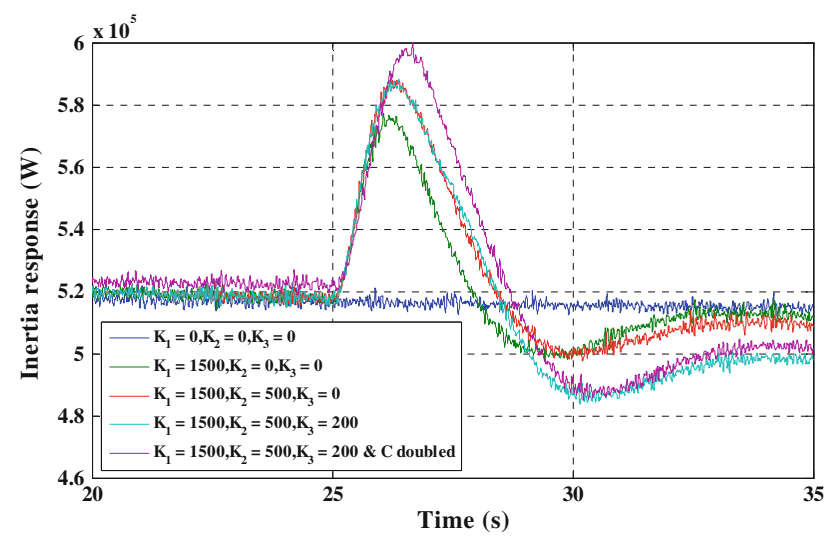

Fig. 12 Inertia response based on the proposed controller

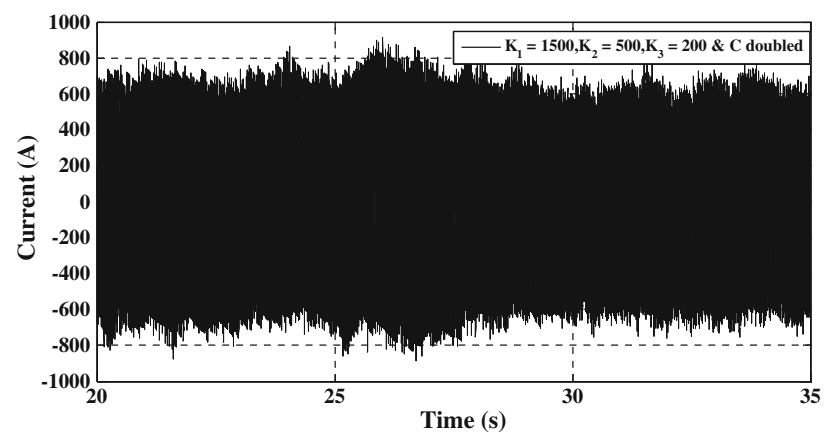

Fig. 13 Grid-side current for the maximum inertia response shown in Fig. 12

changing the gains $K_{1}, K_{2}$, and $K_{3}$ as well as the capacitance of the DC-link capacitors. The inertia response obtained for a frequency change shown in Fig. 11 is shown in Fig. 12.

Figure 12 shows that the turbine with the additional supplementary control loop managed to provide inertia response. An improvement in the response was obtained by modifying the controller gains $\left(K_{1}\right.$ and $\left.K_{2}\right)$. Marginal melioration was observed by utilizing some of the energy stored in the DC-link capacitors; however, when the value of the capacitor was doubled, an improvement was observed in the peak power output and the time at which the rotor starts accelerating.

\section{Effect of inertia response on the converter and DC-link capacitors ratings}

The phase current at the grid coupling during the inertia response for the case when the inertia response was the best is shown in Fig. 13.

As can be observed, the inertia response obtained has small implications on the current rating of the insulatedgate bipolar transistor (IGBT) switches used in the VSC.

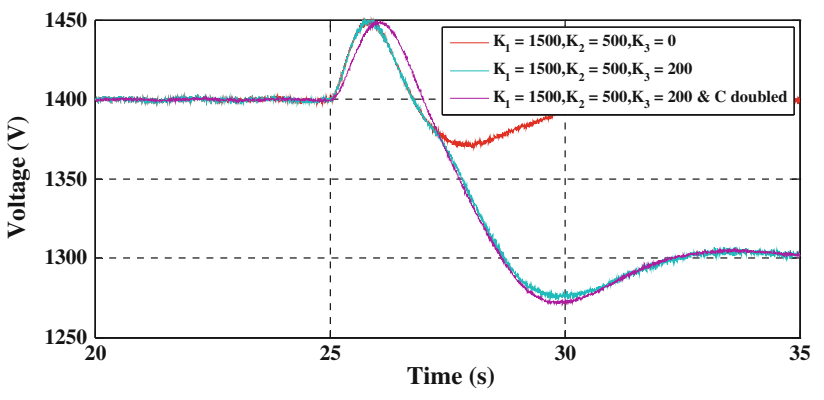

Fig. 14 DC-link capacitors voltage

The current through the devices has increased by less than $15 \%$ for $1 \mathrm{~s}$ compared to their continuous current rating for the operating condition used. Normally, semiconductor devices have a short-term over-current rating which is larger than their continuous rating. Since the inertia response lasts for a few seconds, nominal current-rated IGBTs will be capable of withstanding this short-term over-current without the need to be overrated. This implies that there is no increase in the cost of the devices.

The DC-link voltage is shown in Fig. 14. It can be observed that the voltage increased during the inertia response. This implies that the voltage ratings of the DClink capacitors and converter switches will be affected by the inertia response. Further, the extraction of the stored energy from the DC-link only reduced the voltage by $100 \mathrm{~V}$. This ensures that normal operation of the FRPC wind turbine is maintained during the inertia response. The value of the DC-link capacitor's voltage can be reset to its normal value $(1,400 \mathrm{~V})$ when the system frequency is restored to $50 \mathrm{~Hz}$.

\section{Conclusion}

In this article, the possibility of providing inertia response from wind turbines was demonstrated. Supplementary control signals were added to generator-side and grid-side VSCs to extract the kinetic energy stored in the rotating mass and the energy stored in the DC-link capacitors. The control method used to extract the stored energy in the DC-link capacitors was based on changing the DC-link voltage reference. Substantial improvement was observed in the inertia response when the capacitor was doubled. In theory, this can be improved further if the capacitor voltage is allowed to reduce more. The improvement of the controller is suggested for further study.

The provision of inertia response has a slight implication on the current rating of the IGBTs but has large implication on their voltage rating and that of the DC-link capacitors. 
Acknowledgments This study was supported by the Low Carbon Research Institute (LCRI).

Open Access This article is distributed under the terms of the Creative Commons Attribution License which permits any use, distribution, and reproduction in any medium, provided the original author(s) and the source are credited.

\section{Appendix 1: Wind turbine parameters}

Wind turbine: power rating $=2 \mathrm{MW}$, rotor diameter $=40 \mathrm{~m}$, rated speed $=18 \mathrm{rpm}$, blades $=3$, and air density $=1.225 \mathrm{~kg} / \mathrm{m}^{3}$.

Mechanical model referred to LSS: $J_{1}=6.0289 \times$ $10^{6} \mathrm{kgm}^{2}, \quad J_{2}=416,633 \mathrm{kgm}^{2}, \quad K=1.6 \times 10^{8} \mathrm{Nm} / \mathrm{rad}$, $D=250 \times 10^{3} \mathrm{Nms} / \mathrm{rad}$, and gearbox ratio $=83.33: 1$.

Generator: poles $=4$, frequency $=50 \mathrm{~Hz}$, stator resistance $R_{\mathrm{S}}=4.53 \mathrm{~m} \Omega, d q$ inductances $L_{d}=L_{q}=322 \mu \mathrm{H}$, and $\lambda_{\mathrm{M}}=1.7932 \mathrm{Vs}$.

\section{Appendix 2: Controller parameters}

Pitch controller: $K_{\mathrm{P}}=9.86 \times 10^{-3}$ and $K_{\mathrm{I}}=3.4 \times$ $10^{-3}$; Generator controller-current loop: $K_{\mathrm{P}}=0.166$ and $K_{\mathrm{I}}=33.95 ;$ Grid controller-current loop: $K_{\mathrm{P}}=0.122$ and $K_{\mathrm{I}}=39.3$; and voltage loop: $K_{\mathrm{P}}=9.6$ and $K_{\mathrm{I}}=240$.

\section{References}

[1] Morren J, Pierik J, de Haan SWH (2006) Inertial response of variable speed wind turbines. Electr Power Syst Res 76(11):980-987

[2] Lalor G, Mullane A, O'Malley M (2005) Frequency control and wind turbine technologies. IEEE Trans Power Syst 20(4): 1905-1913

[3] Kayikci M, Milanovic JV (2009) Dynamic contribution of DFIG-based wind plants to system frequency disturbances. IEEE Trans Power Syst 24(2):859-867

[4] Ekanayake J, Jenkins N, Strbac G (2008) Frequency response from wind turbines. Wind Eng 32(6):573-586

[5] Conroy JF, Watson R (2008) Frequency response capability of full converter wind turbine generators in comparison to conventional generation. IEEE Trans Power Syst 23(2):649-656

[6] Tarnowski GC, Kjar PC, Sorensen PE et al (2009) Variable speed wind turbines capability for temporary over-production. In: Proceedings of the Power and Energy Society general meeting (PES'09), Calgary, 26-30 July 2009, p 7

[7] Ullah NR, Thiringer T, Karlsson D (2008) Temporary primary frequency control support by variable speed wind turbinespotential and applications. IEEE Trans Power Syst 23(2):601-612

[8] Ramtharan G, Ekanayake JB, Jenkins N (2007) Frequency support from doubly fed induction generator wind turbines. IET Renew Power Gener 1(1):3-9

[9] National Grid (2004) GB security and quality of supply standard, V1.0. http://www.nationalgrid.com/NR/rdonlyres/A775F8 64-C341-4E80-8A60-0B9BD2EDD78A/1950/GB_SQSS_V1. pdf. Accessed 28 June 2013
[10] Erinmez IA, Bickers DO, Wood GF et al (1999) NGC experience with frequency control in England and Wales-provision of frequency response by generators. In: Proceedings of the Power Engineering Society 1999 winter meeting, New York, 31 Jan-4 Feb 1999, vol 1, pp 590-596

[11] ENTSO-E (2011) Network code on requirements for grid connection applicable to all generators (RfG). http://www.entsoe.eu/ resources/network-codes/requirements-for-generators/. Accessed 28 June 2013

[12] Hydro-Quebec (2009) Transmission provider technical requirements for the connection of power plants to the Hydro-Quebec transmission system. http://www.hydroquebec.com/transenergie/ fr/commerce/pdf/exigence_raccordement_fev_09_en.pdf. Accessed 28 June 2013

[13] National Grid (2010) NGC frequency response technical subgroup. http://www.nationalgrid.com/NR/rdonlyres/F0793C0C9617-49B1-98D4-FAC711F344ED/44455/Meeting2Presentation. pdf. Accessed 28 June 2013

[14] Burton T, Sharpe D, Jenkins N et al (2001) Wind energy handbook, 2nd edn. John Wiley, Chichester

[15] Hansen AD, Michalke G (2009) Multi-pole permanent magnet synchronous generator wind turbines' grid support capability in uninterrupted operation during grid faults. IET Renew Power Gener 3(3):333-348

[16] Geng H, Xu D, Wu B et al (2011) Active damping for PMSGbased WECS with DC-link current estimation. IEEE Trans Ind Electron 58(4):1110-1119

[17] Ramtharan G (2008) Control of variable speed wind generators. Dissertation, The University of Manchester

[18] Krishnan R (2010) Permanent magnet synchronous and brushless DC motor drives. Taylor \& Francis Group, London

\section{Author Biographies}

John LICARI (S'09) was born in Malta, in 1980. He received a B.Eng. (Hons) degree in Electrical and Electronics Engineering from the University of Malta in 2008. He is currently a Ph.D. student at the Institute of Energy at Cardiff University, U.K. His research interests include control of wind turbines, power electronic converters applied to renewable energy sources, power systems, and energy efficiency.

Janaka EKANAYAKE (M'1995, SM'02) was born in Sri Lanka in 1964. He received the B.Sc. degree in Electrical and Electronic Engineering from the University of Peradeniya, Sri Lanka, in 1990, and the Ph.D. degree in Electrical Engineering from the University of Manchester Institute of Science and Technology (UMIST), U.K., in 1995. Since 1992 he has been attached to the University of Peradeniya and was promoted as Professor of Electrical and Electronic Engineering in 2003. He joined the Cardiff University as a Senior Lecturer in 2008, after being a Research Fellow at the University of Manchester. He is a Fellow of the Institute of Engineering and Technology. His main research interests include power electronic applications for power systems and renewable energy generation and its integration.

Ian MOORE was born in England in 1971. He received a B.Eng. (Hons) degree in Electronics and Control from the University of Central England in Birmingham, UK, in 2000 and a Pg.D. in Software Technology in 2001. He worked for a number of years on engine and generator control systems in the commercial aviation industry. In 2008, he received an M.Sc. in Renewable Energy and Distributed Generation from Heriot Watt University in Edinburgh, UK. He is currently a Ph.D. student at the Institute of Energy at Cardiff University, U.K. His research interests are focused on control of wind turbines for large-scale grid integration. 